\title{
La literaturización de la experiencia del exilio como síntesis de la trayectoria política barojiana: el caso de Susana y los cazadores de moscas
}

Palabras clave: narrativa breve española, exilio, Guerra Civil, Generación de 1898, Pío Baroja.

\section{Acercamiento al pensamiento político barojiano}

En el proceso de reconstrucción del complejo universo ideológico barojiano, dos aspectos contribuyen a explicar la ausencia de una reflexión política articulada y coherente: en primer lugar, la personalidad batalladora y el congénito escepticismo del escritor, que lo llevaron a sentir una marcada aversión por cualquier fórmula de gobierno, desde la más conservadora hasta la más revolucionaria; en segundo lugar, sus radicadas convicciones anticlericales y su pronunciada tendencia al individualismo, que ocasionaron frecuentes polémicas a causa de las cuales Baroja se fue alejando progresivamente de la vida pública de su país ${ }^{1}$.

Baroja, en realidad, nunca quiso adherirse a una doctrina específica. Al contrario, su pensamiento se compuso gradualmente, manifestándose a través de las opiniones vertidas a lo largo de sus novelas, ensayos, cuentos y artículos,

1 Baroja siempre amó desempeñar el papel del intelectual esquivo y sui generis. A pesar de esto, en 1901, firmó con Azorín y Maeztu un documento que se considera el primer manifiesto de la Generación de 1898, a la que los tres pertenecieron, en realidad, con empeño y constancia bastante fluctuantes. A pesar del entusiasmo juvenil y de la militancia del escritor en las filas de los intelectuales que luchaban para equiparar España a los demás países europeos, Baroja pronto dejó de reconocerse en los ideales de su generación y dejó de interesarse a las cuestiones políticas y culturales públicas, desarrollando una visión muy personal de la España de su época y criticando la excesiva contaminación entre vida pública y producción artística. 
y mediante una síntesis espontánea entre el imaginario de su juventud y el de su madurez. En este sentido queda justificado el trazado tan variable de su vivencia política, que el novelista aprovechó sobre todo para desafiar las convenciones de su época, experimentando voluntariamente actitudes muy diferentes entre ellas, aunque a menudo bastante contradictorias. Él mismo remarcó la complejidad de sus ideas políticas en 1935, en un discurso oficial frente a la Academia Española:

No fui nunca simpatizante de las doctrinas comunistas. El dogma cerrado del socialismo no me agradaba. Tampoco cogí del anarquismo su pretendida parte constructiva. Me bastaba su espíritu crítico, medio literario, medio cristiano. Después reaccioné contra estas tendencias y me sentí darwinista y consideré, como espontáneamente consideraba en la infancia, que la lucha, la guerra y la aventura eran la sal de la vida (Baroja, 1935: 61).

Baroja empezó a manifestar su interés hacia la política alrededor del año 1909, cuando se vinculó con el partido de Alejandro Lerroux y con ese radicalismo renovador que sedujo a otros intelectuales de su tiempo. El entusiasmo del escritor, sin embargo, fue breve y pronto Baroja empezó a mostrar cierta desafección por la ideología. Como explica Luis Granjel, el novelista empezó entonces a desarrollar un pensamiento político autónomo, que se fue progresiva y peligrosamente acercando a una actitud que el crítico define «despotismo ilustrado» (1992: 29), la cual resulta bien representada por la publicación de la novela César o nada, en que el protagonista, un redivivo César Borgia, pretende cambiar a su modo la realidad de un pequeño pueblo castellano. El núcleo central de la novela lo constituye la exaltación del individualismo del personaje, principio que le hace desconfiar de todo planteamiento colectivo, tanto político como social o cultural ${ }^{2}$. Esta perspectiva fue compartida por el mismo Baroja quien, algunos años después, confesó:

Siempre he tenido recelo y poco amor por la democracia y el comunismo. Ya en todas las manifestaciones democráticas de hace años me parecía ver un peligro. Todos los públicos grandes me han producido desconfianza y, a veces, terror. No

2 La novela se publicó en 1910 y, a causa de los contenidos, Baroja fue acusado de ser un precursor del fascismo. En 1936, el autor contestó a estas acusaciones de manera bastante ambigua: «Yo no me creo un precursor español del fascismo, pero es posible que haya sentido o presentido esa doctrina política como motivo literario» (Baroja, 1938: 93). 
creo que una masa social pueda ir a nada bueno. Todo en ella serán apetitos un poco brutales, nunca pensamientos nobles ni juicios claros (Baroja, 1949, VII: 485).

El acentuado individualismo que define la personalidad del protagonista de la novela se configura como la trasposición literaria de dos rasgos específicos del pensamiento del autor. Por un lado, su evidente desconfianza con respecto a las instituciones oficiales, es decir, la Iglesia, los gobiernos y los partidos políticos, los cuales, desde su punto de vista, habían fracasado en la tarea de solucionar las muchas inquietudes sociales de la época. Por otro lado, debajo del escepticismo que permea la novela late también el profundo pesimismo antropológico barojiano, inspirado por la convicción de que «el hombre es un animal egoísta» (Baroja, 1949, VII: 981), eso es, un ser intrínsecamente incapaz de olvidarse de sus exigencias personales y de resolver el conflicto entre la necesidad del cambio y la búsqueda de esa seguridad personal que todo hombre desea alcanzar, aunque sea con pérdida del bien colectivo.

Cerrado este brevísimo paréntesis de militancia política, Baroja volvió a ocuparse de su producción literaria y recibió la noticia de la proclamación de la Segunda República, en 1931, con cierto escepticismo (Uribe Echevarría, 1957: 154). Con respecto a lo que estaba pasando en Europa en ese mismo período, Julio Caro Baroja, sobrino del escritor, anota que a su tío le preocupó mucho la ascensión de Hitler en Alemania y que experimentó por Mussolini una «antipatía casi física» (1962: 38). Sin embargo, Caro Baroja añade también que el novelista «hubiera visto con gusto un ensayo de dictadura reformista y radical» (1962: 38 ), soñando, a veces, que un solo hombre pudiera resolver todos los problemas de España. El desdeñoso desinterés que Baroja mostró frente a las reacciones suscitadas por estas convicciones políticas contribuyó naturalmente a empeorar su fama de pensador conservador y reaccionario. Para muchos de sus delatores, en efecto, resultaba difícil comprender que, a pesar de sostener ideas radicales, el novelista pudiera seguir mostrándose tan reticente en aceptar los nuevos ímpetus revolucionarios. Malquerido por los republicanos e igualmente censurado por los conservadores, que lo acusaron repetidas veces de no quererse realmente comprometer con su causa política, Baroja empezó entonces a interrogarse acerca de la oportunidad de adscribirse a uno de los dos bandos en lucha:

Ante una situación así de los escritores españoles, confusa y al mismo tiempo precaria, no se sabe qué hacer. ¿Decidirse por un lado o por otro? Es difícil sin violentar el espíritu. 
¿No decidirse ni por los unos ni por los otros? También es difícil desde el punto de vista práctico. ¿A dónde ir? (Baroja, 1998: 35).

Como resultado de estas atormentadas reflexiones, Baroja llegó en un primer momento a declararse contrario a los fervores revolucionarios y a convencerse de que una dictadura militar quizás podría incluso constituir una posible vía de salvación para el país. Luego, como era inevitable, él tampoco pudo aceptar el credo ideológico impuesto por los que triunfaron en la contienda y apoyó formalmente la causa republicana desde el exilio francés. Más adelante, de vuelta a su tan querida España destruida y violada por la guerra civil, se alejó definitivamente de la vida política pública para refugiarse en un nuevo y más amargo escepticismo que lo acompañó en los últimos años de su carrera literaria.

\section{El exilio francés}

Cuando en 1936 estalló la guerra, Baroja se encontraba con su familia en la casa de Vera de Bidasoa. El escritor estaba entonces atravesando un período difícil debido, por un lado, a la muerte de la madre, ocurrida el año precedente, y por otro, a su ya mencionada desilusión con la labor de una clase política decepcionante que se estaba demostrando ineficaz a la hora de resolver las muchas tensiones sociales en España. José-Carlos Mainer ha definido esta peculiar actitud del novelista como una suerte de «melancolía racionalista propia de un conservador ilustrado y laico» (2012: 317) que todavía se encontraba muy lejos de sospechar cómo cambiarían las cosas en brevísimo tiempo.

Los resultados de la sublevación militar en Marruecos tardaron algunas semanas en manifestarse concretamente en las zonas de las provincias del norte del país y, mientras tanto, Baroja se acostumbró a caminar por las carreteras del pueblo para asistir a los preparativos de los nacionalistas. El día 22 de julio de 1936, uno de los soldados reconoció y delató al escritor, que fue encarcelado a causa de sus pasadas simpatías políticas (Flores Arroyuelo, 2008: 172). Sin embargo, gracias a la intercesión de un jefe militar local, admirador de su obra literaria, se le puso en libertad el día siguiente 3 . Baroja tomó entonces la decisión de cruzar la frontera francesa, empezando así su exilio voluntario. Algunos años después, el novelista consignó sus impresiones de esos primeros

3 Los concitados acontecimientos de aquellos días fueron reconstruidos por el mismo autor en algunas entrevistas concedidas a Miguel Pérez Ferrero, uno de sus biógrafos oficiales, el cual, a su vez, las recogió en un volumen titulado Pío Baroja en su rincón, publicado en 1941. 
días de la guerra en un libro titulado La guerra civil en la frontera ${ }^{4}$, en cuyo prólogo nos explica que «en algunas circunstancias las impresiones de las vidas vulgares, contadas con exactitud y detalles, pueden tener algún interés y dar el carácter de la época» (Baroja, 2005: 5) con la misma precisión que el simple relato de las más notorias hazañas bélicas 5 . Como se deduce de estas palabras, Baroja no quiso dedicarse a la reconstrucción de los acontecimientos y prefirió, al contrario, la descripción de sus efectos en las vidas de las personas comunes. Sin embargo, siempre quiso mantenerse al corriente de los crímenes que se estaban cometiendo en España (Sánchez-Ostiz, 2000: 152).

Hacia finales de septiembre de 1936, el escritor se trasladó a París, donde residió en el Colegio de España de la Ciudad Universitaria, lugar en el que pudo compartir sus ideas con otros intelectuales españoles que aguardaban allí el desenlace de la guerra. En abril de 1937 viajó a Suiza y el 13 de septiembre regresó a España. Sin embargo, a principios del año siguiente, el escritor decidió volver otra vez a Francia, tanto por razones de seguridad personal como, sobre todo, por no gravar la economía familiar, que en esa época era bastante precaria. A partir de ese momento, Baroja residió en diferentes lugares de la capital francesa hasta el día 24 de junio de 1940, cuando, logrado el necesario salvoconducto, volvió definitivamente a España.

En los primeros meses del exilio, para sustentarse económicamente Baroja aceptó el ofrecimiento del diario La Nación de Buenos Aires, para el que comenzó a escribir artículos. Esta colaboración, que se concluyó en 1943, representó su principal sostén económico en el destierro pero el autor mantuvo también otras colaboraciones periodísticas con el semanario mexicano Hoy y con algunos diarios franceses. Además, siguió dedicándose a la publicación de libros recopilatorios y a la escritura de obras nuevas. En particular, su larga estancia parisina fue el marco fundamental de tres novelas: Susana y los cazadores de moscas, impresa en 1938, Laura, o la soledad sin remedio, impresa en 1939, y El botel del cisne, impresa en $1946^{6}$. En esa misma temporada, Baroja escribió tam-

4 Los primeros siete volúmenes de las memorias de Baroja, tituladas Desde la última vuelta del camino, fueron publicados en entregas semanales, entre septiembre de 1942 y noviembre de 1943. El octavo volumen, titulado La guerra civil en la frontera, al contrario, permaneció celosamente guardado por decisión familiar durante algo más de cincuenta años y se publicó en 2005.

5 En las palabras citadas parece más que evidente la influencia del concepto de intrabistoria elaborado por Miguel de Unamuno y tan caro a la mayor parte de los autores de la Generación de 1898.

6 Susana y Laura, en particular, materializaron el propósito de Baroja de reanudar su labor como escritor insatisfecho de su trabajo de articulista que daba sostén económico a su vida de exiliado. 
bién dos volúmenes misceláneos de ensayos titulados respectivamente Aquí, París y Paseos de un solitario, que se publicaron en 1955.

El autor redactó la mayor parte de estas obras durante su estancia en Francia y sólo una pequeña parte fue terminada tras su regreso a España. En todas ellas, además, no quiso reconstruir los acontecimientos históricos como una continuidad orgánicamente entrelazada sino que se volvió a la historia porque vio en ella, como explicado por Carlos Longhurst, una manifestación del «humano existir en todo su dinamismo» (1974: 250).

\section{Baroja frente a la Guerra Civil: el caso de Susana y los cazadores de moscas}

En las ficciones literarias barojianas posteriores al año 1936 es posible deslindar un bloque compuesto por tres novelas breves acomunadas por el hecho de presentar, como telón de fondo, la Guerra Civil española y cuyos protagonistas, todos desplazados a causa del conflicto, experimentan las mismas dificultades vividas por el novelista en los años del destierro. En Paseos de un solitario, Baroja cita una de estas tres novelas y nos describe su génesis de la siguiente manera:

El trastorno que nos produjo la guerra civil española me hizo que me apartara de escribir novelas de ambiente político y social a que antes de estallar aquélla me dedicaba, y, una vez en París, simultaneando mi trabajo con la redacción de algunos artículos periodísticos para la prensa sudamericana, me puse a escribir una novela de ambiente parisiense, que fue Susana y los cazadores de moscas (Baroja, 1955: 157).

La redacción de la novela titulada Susana y los cazadores de moscas empezó en París durante el primer año del exilio barojiano, siguió durante su viaje a Suiza y se concluyó en la capital francesa en 1938. Como ha reconstruido por Miguel Ángel García de Juan (2007: 41), el texto fue publicado por primera vez por una pequeña editorial donostiarra ${ }^{7}$ y luego la editorial barcelonesa Juventud volvió a imprimirlo en 1941. Al principio, además, el título de la novela consistía únicamente en el antropónimo de la coprotagonista femenina pero, en un segundo momento, el escritor decidió prolongarlo para evitar que evocara otras narraciones suyas de la época juvenil y de tema exclusivamente amoroso.

7 Se trata de la editorial Bimsa, cuya sede se encontraba en la ciudad de San Sebastián, que publicó la novela en 1938 . 
El argumento desarrollado en el texto es bastante sencillo. Miguel Salazar es un joven farmacéutico madrileño que tiene que viajar a Francia por cuestiones de negocios. Durante su estancia en París, sin embargo, estalla la Guerra Civil y el joven se ve imposibilitado a regresar a España. Por consiguiente, se ve también forzado a instalarse en la capital francesa donde vive las penurias de su imprevisto exilio rodeado por un sugestivo grupo de españoles, igualmente exiliados, y por algunos excéntricos artistas franceses. Poco a poco, Salazar se enamora de la hija de uno de ellos, Susana, pero sus sueños quedan de repente truncados por la muerte prematura de la chica. El protagonista decide entonces volver a España, donde vive los últimos meses del conflicto, trabajando como profesional en un laboratorio de análisis químicos.

Desde el punto de vista teórico, la novela presenta todos los rasgos típicos del discurso autobiográfico, puesto que se puede definir la autobiografía como una tentativa de narración objetiva y verídica de la vida individual. El género, según la crítica, pertenecería al ámbito de los escritos de no ficción y, en él, el yo narrativo resultaría ser contemporáneamente el sujeto y el objeto principal de la narración ${ }^{8}$. La estructura narrativa de la novela Susana y los cazadores de moscas, en efecto, corresponde a la de una confesión íntima, escrita en primera persona, que Miguel Salazar le dirige a una amiga de su hermana para ponerla al corriente de sus recientes desventuras. Su discurso, pues, es una larga analepsis que le permite dirigir la mirada hacia el pasado para volver a contar y ordenar cronológicamente un período de su vida, enfocándolo esta vez desde una perspectiva diferente. Como a menudo pasa en los relatos autobiográficos, además, Salazar es un narrador autodiegético y, por consecuencia, toda la información que los lectores reciben acerca de su vida y de su personalidad depende de la visión que él mismo decide proporcionarles.

El carácter de Salazar se manifiesta ya desde las primeras líneas de la novela, en las que el narrador y protagonista absoluto de la historia desgrana personalmente las peculiaridades intelectuales, morales y físicas que lo caracterizan:

Soy hombre aplicado, trabajador y, en gran parte, autodidacto. Lo que sé bien, lo he aprendido por mi propio esfuerzo, sin ayuda de nadie [...] Soy un carácter un tanto independiente, infantil y tímido; no sé tampoco mentir con gracia, ni darme

8 Según el estudio de Philippe Lejeune publicado en 1975 y titulado Le Pacte autobiograpbique, se trataría de las características principales que intervienen al momento de estipular cualquier pacto autobiográfico entre el autor y los lectores. Al faltar una sola de ellas, sería imposible atribuirle a la narración el carácter de autobiografía. 
importancia. [...] De tipo, creo que soy corriente: alto, más bien rubio, de buen color y con ojos claros. Visto con trajes baratos, comprados en bazares, y no me destaco por nada (Baroja, 1949, VII: 10).

Después de haberse presentado como un hombre meticuloso pero insignificante, Salazar pasa a explicar los cambios que la experiencia del exilio forzado ha producido en su personalidad. Con este propósito señala que antes de llegar a París era un hombre melancólico y de ideas pesimistas mientras que, después del paréntesis parisino, se descubre más bien «como hombre un poco fantástico y sentimental» (1949, VII: 9), a pesar de reconocer que esta misma evolución caracterial dependió más de las circunstancias externas que de su espontánea propensión al cambio.

Haciendo recurso a un artificio bastante común en su producción narrativa, Baroja estableció varios paralelismos entre las experiencias vividas por el protagonista y su propia biografía. Salazar, por ejemplo, fija su residencia parisiense en un espacio muy próximo a los lugares en que vivió el novelista en París y afirma que le gusta dar paseos solitarios por las mismas calles recorridas por el escritor vasco. Además, él también trabaja duramente para enviarle dinero a su familia que se ha quedado en España y presencia con cierta decepción la inauguración de la Exposición Universal de $1937^{9}$.

Más allá de las mencionadas correspondencias de fechas y lugares entre la vida de Salazar y la de Baroja, el novelista quiso complicar la estructura autobiográfica de la novela mediante una consciente superposición de los papeles de autor y personaje. Por esta misma razón, pues, quiso trasladar al personaje distintos aspectos de su propia forma de pensar, ser y actuar. En este sentido, varios matices de la personalidad de Salazar son barojianos y, por lo tanto, autobiográficos: la innata timidez, el individualismo, la tendencia a callejear y observar, la impresión muy temprana de adultez que transmite, el pesimismo, los gustos literarios, la actitud crítica frente al complejo de superioridad francésa y hasta el estilo narrativo, hecho de párrafos cortos y frases breves que logran reproducir perfectamente el «tono menor» barojiano (Galbis, 1976: 225). Por otro lado, fue el mismo Baroja quien confirmó que Miguel Salazar podía en parte considerarse el trasunto de la personalidad de su creador, añadiendo también que había querido incorporar en ese personaje parte de su propia vida

9 Baroja no quiso visitar la Exposición Universal que se inauguró en París en la primavera de 1937 y en su personaje se hace patente la misma actitud desinteresada hacia el evento (1949, VII: 47). 
e introducir en su psicología «las perplejidades por que pasaba yo en tiempos que tardaron en aclarar un poco» (Baroja, 1955: 157).

En la novela, sin embargo, el autor no se limitó a darle un corte autobiográfico a la personalidad del protagonista, sino que se introdujo a sí mismo en el relato bajo el semblante de un anónimo y anciano escritor madrileño, también refugiado en París, que se autodescribe con palabras muy significativas, las cuales resumen, una vez más, la condición psicológica del novelista en los años del destierro:

Como yo no tengo muchas condiciones para vivir entre la gente y estoy aquí solo, me esfuerzo en ver si puedo confundirme con la gente, pero no puedo. Ando entre la multitud, miro una plaza iluminada de noche, pero no hago más que aburrirme, y me encuentro más solo que en mi cuarto (Baroja, 1949, VII: 18).

Al observar el estado de tristeza y decaimiento físico en el que se halla este segundo alter ego barojiano, Salazar constata que «debía de ser terrible la vida de aquel hombre. Solo, viejo y abandonado en una gran ciudad» (Baroja, 1949, VII: 14) y, más adelante, lo interpreta como una metáfora de la precariedad de la existencia humana, dominada por «aburrimiento y tristeza» (Baroja, 1949, VII: 16).

Diferentemente de lo que hizo en otros cuentos y novelas, Baroja no intervino en esta narración para empezar alguna polémica o para ridiculizar alguna actitud sino, más bien, para revelar, aunque indirectamente, su propio estado de ánimo. Sin embargo, las abundantes referencias autobiográficas del texto no se limitan a la descripción del temperamento de los personajes mencionados hasta ahora y se manifiestan también en su disposición hacia la realidad que los rodea. Salazar comparte así la perspectiva barojiana acerca de la metrópoli y su mirada le corresponde a la del artista moderno que busca su inspiración en el espectáculo incesante de la calle más que en la contemplación de la grandiosidad monumental de la ciudad. Lo que complica las cosas es que el personaje experimenta al mismo tiempo la soledad, el desengaño y la angustia provocados por la conciencia de no pertenecer culturalmente a esa misma realidad que está observando. De ahí, pues, surgen sus amargas reflexiones:

Yo sabía que en París era un extranjero corriente y vulgar; no esperaba la más pequeña atención. Por otra parte, no tenía espíritu de turista. No lo había tenido nunca, y el ver iglesias, avenidas, palacios y fuentes no me producía entusiasmo. Tampoco me gustaba andar huyendo de los autos como un conejo entre cazadores (Baroja, 1949, VII: 16). 
A pesar de las tentativas de Susana, que le hace de guía turística por la ciudad, Salazar sigue mostrando la misma falta de entusiasmo a lo largo de todo el relato hasta convertirse en un crítico riguroso de los aspectos negativos de la metrópoli, los que le procuran una sensación de vértigo, desde la desolación de los barrios periféricos hasta la tétrica gravedad de las fachadas de los palacios más céntricos, cuyo pasado le recuerda trágicas historias de muerte (Erdozáin, 2008: 9).

Por otra parte, las dotes de observador y las habilidades descriptivas de Baroja ya se habían configurado como características constantes de su estilo narrativo y el novelista no renunció a retratar con abundancia de detalles todos los lugares que había conocido personalmente. En el texto, sin embargo, su mirada no queda circunscrita a la geografía y al aspecto exterior de la capital francesa sino que se extiende hasta querer captar la personalidad de quien la habita, con una técnica muy parecida a la de las rápidas pinceladas impresionistas que esbozan con prontitud y ligereza sólo los rasgos necesarios a la caracterización de las personalidades (Corrales Egea, 1969: 46). En algunos pasajes del texto, pues, el autor logra crear una perfecta sintonía entre las atmósferas de los ambientes y el temperamento de los personajes. Por esta misma razón, a los españoles residentes en París les corresponden hogares míseros y despersonalizados que reproducen simbólicamente las angustias de los exiliados. Es el caso, por ejemplo, del primer hotel en el que Salazar vive junto con un grupo heterogéneo de individuos: un médico huido de España con su esposa en un momento de pánico colectivo, un grupo de malagueños que en París se dedican al comercio de las frutas y una viuda de guerra. Todos ellos arrastran una existencia mísera e infeliz que se refleja en el aspecto tristón y descuidado de la pensión en la que han decidido vivir. La misma impresión de desolación y pobreza aproxima Salazar al joven Juan Semper, farmacéutico catalán que sobrevive en una modestísima residencia universitaria gracias a una pequeña pensión del gobierno, y a otro grupo de jóvenes estudiantes españoles expatriados sin particulares recursos económicos.

Con respecto a estos últimos, sin embargo, hace falta subrayar una diferencia substancial que se hace más manifiesta cuando se presenta por primera vez la cuestión de la Guerra Civil. Al recibir la noticia del conflicto, los estudiantes españoles reaccionan con superficial indiferencia mientras que, compartiendo la misma opinión del autor, el protagonista anota, al comienzo del tercer capítulo:

Ante un acontecimiento de tal magnitud como la conmoción de España, quedé en un estado de perplejidad. No sabía qué 
hacer, no conocía a nadie en París. Pensé que la cuestión española sería solamente asunto de días y que valdría más que volver a Madrid en seguida esperar a que la situación política se despejara (Baroja, 1949, VII: 12).

Al recibir noticias cada día más alarmantes, Salazar realiza que la situación es más grave de lo que parece y critica a sus compatriotas que, al contrario, siguen mostrando la misma actitud indiferente y despreocupada de siempre. Cuando puede, pues, les reprocha, les hace notar que «los españoles no estamos en el momento de malas bromas» (1949, VII: 18) y que sería oportuno mantener por lo menos cierta compostura como seña de solidaridad hacia los que se han quedado en España.

Tampoco los amigos franceses del protagonista muestran alguna curiosidad hacia lo que está pasando en la península y se limitan a hacer preguntas bastante vagas sin estar realmente interesados en el asunto. Es más, cuando la conversación converge hacia el tema, muchos de ellos sacan a relucir ideas totalmente estereotipadas acerca de los españoles, delatando así toda su ignorancia y superficialidad. Salazar las resume con amarga ironía en uno de los párrafos más significativos de la novela:

Se habló después de España. Unos decían que España era un volcán, que todos los españoles éramos fanáticos y energúmenos; otros aseguraban que España era un país tan libre como cualquiera. Una señora afirmó que en España las mujeres no pensaban más que en sus hijos y no hacían vida de sociedad. El señor Olivier, el amo de la casa, insinuó si los españoles serían gente desencantada, quizá demasiado ambiciosos, porque él creía notar esto lo mismo en Séneca que en Cervantes, en Ignacio de Loyola como en los conquistadores (Baroja, 1949, VII: 36).

El tema de la guerra constituye el punto de arranque y el telón de fondo de la novela, aunque los personajes la perciban más como un lejano presentimiento que como una amenaza concreta. Por esta misma razón, la cuestión aparece escasamente mencionada en la obra, como si la distancia geográfica pudiera contribuir de alguna forma a mitigar los miedos y las preocupaciones de los protagonistas.

A pesar de esta peculiar elección, Baroja nunca quiso mantenerse al margen de los discursos oficiales acerca del conflicto (Martín, 1975: 120). El autor, al 
contrario, dejó amplia información sobre aquellos años dramáticos en diversos escritos suyos, muchos de los cuales tuvieron problemas con la censura (Reig Tapia, 2007: 617). En ellos, Baroja criticó ásperamente las decisiones políticas de la derecha más reaccionaria y, sin embargo, sus juicios más severos los dirigió hacia esos españoles que, independientemente de su credo político, aprovecharon la ocasión para desahogar sus más recónditos y connaturales deseos de venganza, sus odios personales y sus frustraciones:

En la guerra civil alienta el odio más puro, porque no sólo se quiere vencer, sino castigar al enemigo; hay la pedantería unida a la tendencia al sadismo, la defensa de la doctrina aliada al placer de matar y de hacer sufrir. En la guerra civil todas las maldades están reunidas (Baroja, 1998: 151).

Diferentemente de su creador, los protagonistas de Susana y los cazadores de moscas prefieren evitar el asunto y dedicarse a todo tipo de actividad que les pueda hacer olvidar, aunque sólo por un momento, las atrocidades que se están cometiendo en España. Tampoco la sociedad parisina retratada en el texto, además, se muestra interesada en la tragedia española. Ni Susana ni su padre, por ejemplo, hacen alguna alusión directa a la guerra y las únicas preguntas que le dirigen a Salazar sirven para satisfacer su personal curiosidad con respecto a la cultura de un país que ambos consideran algo exótico.

Al describir el padre de Susana, el protagonista de la novela lo presenta como un hombre de aire bohemio y galante con las mujeres. Baroja, sin embargo, se identifica parcialmente con la figura del pintor francés y le atribuye rasgos propios de su pensamiento como, por ejemplo, las opiniones negativas acerca de los movimientos de vanguardia, la crítica hacia el positivismo decimonónico y el interés por las filosofías orientales. Roberts es también el fundador de una sociedad secreta que reúne a varios intelectuales y artistas parisienses, vinculados por el objetivo de llevar a cabo el exterminio de las moscas, como recita el título de la novela. Esta obsesión, que representa el leitmotiv de sus charlas y encuentros, puede metafóricamente interpretarse desde dos perspectivas: por un lado, las moscas representarían los aspectos más triviales de la existencia y en este sentido la importancia que los personajes les atribuyen se convertiría en el símbolo de una generalizada falta de valores que caracterizaba, según Baroja, la sociedad española de su época; por otro lado, la imposibilidad de alcanzar el objetivo final sería una metáfora de la condición existencial del hombre moderno, obligado a luchar constantemente para defender sus sueños e ideales. 
Esta misma idea quedará confirmada por el contacto directo con la muerte y con las atrocidades de la guerra que Salazar experimenta en los capítulos finales de la novela. La experiencia lo acerca, una vez más, al mismo Baroja. Salazar, propio como el escritor vasco, se vuelve a descubrir pesimista y resignado frente a la implacabilidad del destino. Al mismo tiempo, sin embargo, reconoce que el sufrimiento le ha permitido madurar y lo ha convertido en un hombre más fuerte y enérgico. Esta actitud ambivalente puede tener, según los críticos, una doble interpretación. Por un lado están Laín Entralgo, Granjel y Recaséns que, en sus estudios la vuelven a interpretar a la luz de la época histórica, buscando sus causas en el choque entre la frustración del autor, en desacuerdo radical con las estructuras sociales de su tiempo, y su personal tendencia a la rebelión contra las injusticias. Por otro lado, Azcárraga y Torrente Ballester sostienen que la ambigüedad de Baroja fue más bien de orden temperamental, lo que justificaría la resignada parálisis del personaje frente al curso de los acontecimientos pero también su deseo de oponerse polémicamente a la obtusa pasividad de sus compatriotas ${ }^{10}$.

\section{Conclusiones}

La personalidad contradictoria de Baroja, su temperamento polémico pero, sobre todo, la mencionada ambigüedad de sus posiciones políticas contribuyeron a que su memoria quedara relegada, especialmente en los años ' 40 y '50 del siglo pasado, a lo que José-Carlos Mainer ha definido el «purgatorio del escritor» (2012: 373). Sin embargo, a partir de los años '6o, la crítica ha vuelto a recuperar su memoria, rescatando muchas de sus obras del olvido. Los análisis más recientes, pues, han demostrado y siguen demostrando que Baroja fue uno de los observadores más rigurosos y atentos de la compleja realidad histórica de su época y asimismo uno de los autores que más acertaron en darle una correcta interpretación y representación en sus textos.

Más allá de las posibles lecturas que se le pueden dar a la novela que se acaba de analizar, los críticos han también reconocido que la publicación de Susana y los cazadores de moscas marcó una etapa fundamental en el conjunto de la producción narrativa barojiana. El protagonista, como demostrado, encarna

10 Recaséns Díaz de León (1958) en su estudio dedicado al tema del individualismo barojiano y Laín Entralgo (1997) y Granjel (1992), en sus estudios dedicados a la Generación de 1898, subrayan los paralelismos entre la producción artística de Baroja y el contexto histórico en que le tocó vivir. Al contrario, Azcárraga (1947) y Torrente Ballester (1965) insisten en la importancia de la componente temperamental en la construcción del imaginario político barojiano. 
perfectamente la crisis emotiva del autor en los años del exilio pero también logra personificar las principales inquietudes filosóficas y las hondas preocupaciones por el destino de España que caracterizaron no sólo el pensamiento de Baroja sino también el de todos los intelectuales de su tiempo. Por esta misma razón, la novela se presenta como la síntesis de actitudes contrastantes que van de la estoica resignación del protagonista frente a la inexorabilidad del destino que le ha tocado hasta su rebelión final. Miguel Salazar, álter ego barojiano, es la trasposición literaria del pesimismo de su creador y, sin embargo, este mismo pesimismo quizás pueda interpretarse, a la luz del atormentado destierro barojiano, no tanto como un símbolo de la derrota del ser humano frente a la acción del destino sino, más bien, como una invitación del novelista a vencer el estéril individualismo en que todos nos refugiamos frente a las dificultades de la vida para defender, con renovado ímpetu y vigor, nuestros derechos y libertades.

\section{Bibliografía}

Azcárraga, A. de (1947): La timidez sentimental de Baroja, el cine ¿séptimo arte? y otros ensayos. Valencia: Aeternitas.

Baroja, P. (1998): Ayer y boy. Madrid: Caro Raggio.

Baroja, P. (1938): Comunistas, judios y demás ralea. Valladolid: Reconquista.

Baroja, P. (1935): La formación psicológica de un escritor. Madrid: Espasa Calpe: http://www.rae.es/sites/default/files/Discurso_ingreso_Pio_Baroja.pdf, (13-06-2015).

Baroja, P. (2005): La Guerra Civil en la frontera. Madrid: Caro Raggio.

Baroja, P. (1949): Obras completas. Madrid: Biblioteca Nueva.

Baroja, P. (1955): Paseos de un solitario. Madrid: Biblioteca Nueva.

Caro Baroja, J. (1962): Pío Baroja y su mundo. Madrid: Arion.

Corrales Egea, J. (1969): Pío Baroja y Francia. Madrid: Taurus.

Erdozáin, A. I. (2008): «Baroja y París. Una representación sociológico-literaria de la gran ciudad con referencia a Tönnies y Simmel». SymCity, 2, 1-11.

Flores Arroyuelo, F. J. (2008): «Pío Baroja y Francia: Política, exilio e intriga». Barcarola. Revista de creación literaria, 71-72, 161-173.

Galbis, I. R. M. (1976): Baroja, el lirismo de tono menor. Nueva York: Torres.

García de Juan, M. Á. (2007): Las novelas parisienses de Pío Baroja. Madrid: Caro Raggio. 
Granjel, L. S. (1992): El último Baroja. Salamanca: Artes Gráficas.

Laín Entralgo, P. (1997): La generación del 98. Madrid: Espasa Calpe.

Lejeune, P. (1986): Il Patto autobiografico. Bologna: Il Mulino.

Longhurst, C. (1974): Las novelas bistóricas de Pío Baroja. Madrid: Guadarrama.

Mainer, J. C. (2012): Pío Baroja. Madrid: Taurus.

Martín, E. (1975): «La actitud de Pío Baroja ante la guerra civil española». Cabiers du monde bispanique et luso-brésilien, 25, 119-133.

Pérez Ferrero, M. (1941): Pío Baroja en su rincón. Madrid: Editora Internacional.

Recaséns Díaz de León, M. (1958): «La soledad de Pío Baroja. Su individualismo frente a la sociedad». La Torre, 6, 91-116.

Reig Tapia, A. (2007): «Los intelectuales y la guerra civil: los casos de Unamuno y Baroja». Historia Contemporánea, 35, 601-622.

Sánchez-Ostiz, M. (2000): Derrotero de Pio Baroja. Zarautz: Alberdania.

Torrente Ballester, G. (1965): Panorama de la literatura española contemporánea. Madrid: Guadarrama.

Uribe Echevarría, J. (1957): «Pío Baroja: técnica, estilo, personajes». Anales de la Universidad de Chile, 6, 151-199. 


\section{Francesca Crippa}

Catholic University Sacro Cuore (Milano)

\section{The literary vision of the exile as a synthesis of Baroja's political experience: the case of Susana y los cazadores de moscas}

Keywords: Spanish short narratives, exile, Civil War, Generation of 1898, Pío Baroja.

In his short novel titled Susana y los cazadores de moscas (1938), Baroja tells the story of an ordinary person who finds himself compelled to live in another country because of the Civil War. Baroja partially identifies himself in his main character, whose name is Miguel Salazar, because he himself had to build a new life in Paris, where he decided to go after the war broke out. The aim of this work is to analyze the novel according to the ideological and biographical correspondences between the author and the main character in order to confirm the possibility of an autobiographical interpretation for one of the less known novels written by the Basque writer. 


\section{Francesca Crippa}

Katoliška univerza Sacro Cuore v Milanu

\section{Literarizacija izkušnje izgnanstva kot sinteza politične poti Pía Baroje: primer romana Susana y los cazadores de moscas}

Ključne besede: španska kratka proza, izgnanstvo, državljanska vojna, generacija 1898, Pío Baroja

V kratkem romanu Susana y los cazadores de moscas [Susana in lovci na mube] (1938) nam Baroja pove zgodbo o nekem povsem običajnem moškem, ki se je zaradi izbruha španske državljanske vojne primoran izseliti v tujino. Baroja se tako delno poistoveti s protagonistom, saj si je moral tudi sam na novo urediti življenje v Parizu, ko je ob izbruhu vojne sklenil prostovoljno oditi v Francijo. Namen tega prispevka je v luči analize Barojove politične misli in vsebine obravnavanega dela pokazati na številna biografska in ideološka ujemanja med avtorjem in literarno osebo ter prispevati k utemeljitvi, zakaj enega od manj znanih romanov iz književnega opusa baskovskega pisatelja lahko beremo po avtobiografskem ključu. 